\title{
Erratum: Decision checkpoint in the thymus
}

Andreas C Carpenter \& Rémy Bosselut

Nat. Immunol. 11, 666-673 (2010); published online 20 July 2010; corrected after print 2 September 2010

In the version of this article initially published online, no Competing Financial Interest statement was included. The authors declare no competing financial interests. The error has been corrected for all versions of this article.

\section{Erratum: IL-1 family nomenclature}

Charles Dinarello, William Arend, John Sims, Dirk Smith, Hal Blumberg, Luke O’Neill, Raphaela Goldbach-Mansky, Theresa Pizarro, H Hoffman, Philip Bufler, Marcel Nold, Pietro Ghezzi, Alberto Mantovani, Cecilia Garlanda, Diana Boraschi, Anna Rubartelli, Mihai Netea, Jos van der Meer, Leo Joosten, Tom Mandrup-Poulsen, Marc Donath, Eli Lewis, Josef Pfeilschifter, Michael Martin, Michael Kracht, H Muehl, Daniela Novick, Miodrag Lukic, Bruno Conti, Alan Solinger, Kelk Peyman, Frank van de Veerdonk \& Chiristopher Gabel Nat. Immunol. 11, 973 (2010); published online 19 October 2010; corrected after print 10 Jan 2011

In the version of this article initially published, the author name Peyman Kelk was inverted. The error has been corrected in the HTML and PDF versions of the article.

\section{Corrigendum: IAPP boosts islet macrophage IL-1 in type 2 diabetes}

Thomas Mandrup-Poulsen

Nat. Immunol. 11, 881-883 (2010); published online 20 September 2010; corrected after print 21 October 2010.

In the version of this article initially published, some of the text on p 882 was inaccurate. The correct text should read as follows: "thereby counteracting the beneficial effects of blocking IAPP on islet inflammation" (middle column) and "This mechanism has been suggested to mediate ROSdependent inflammasome activation induced by high concentrations of glucose in mouse pancreatic beta cells ${ }^{12}$, although this finding is now being debated" (right column, first full paragraph, second sentence). The errors have been corrected in the HTML and PDF versions of the article.

\section{Corrigendum: A model for harmonizing flow cytometry in clinical trials}

Holden T Maecker, J Philip McCoy Jr \& the FOCIS Human Immunophenotyping Consortium

Nat. Immunol. 11, 975-978 (2010); published online 19 October 2010; corrected after print 12 November 2010

In the version of this article initially published, a group of author names and their affiliation in the FOCIS Human Immunophenotyping Consortium was incorrect. The correct names and affiliation are as follows: Paola Di Meglio, Frank O. Nestle, Mark Peakman and Federica Villanova are at King's College London, London, UK. The error has been corrected in the HTML and PDF versions of the article.

\section{Corrigendum: Phosphatase SHP-1 promotes TLR- and RIG-I-activated production of type I interferon by inhibiting the kinase IRAK1}

Huazhang An, Jin Hou, Jun Zhou, Wei Zhao, Hongmei Xu, Yuejuan Zheng, Yizhi Yu, Shuxun Liu \& Xuetao Cao Nat. Immunol. 9, 542-550 (2008); published online 6 April 2008; corrected after print 22 December 2010

In the version of this article initially published, the actin loading control in Figure $6 \mathrm{~b}$ (left) was incorrect. The correct figure is provided here. The error has been corrected in the HTML and PDF versions of the article.

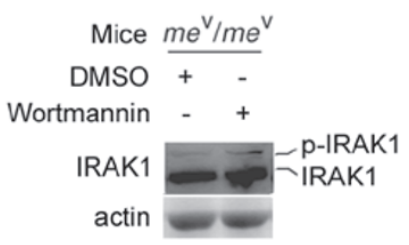

